\title{
Communicative aspects of assertive behavior of the elderly
}

\author{
L. V. Viktorova*, K. O. Chulkova
}

\author{
National University of Life and Environmental Sciences of Ukraine \\ *Corresponding author. E-mail: viktorova17@ukr.net
}

Paper received 01.08.18; Accepted for publication 09.08.18.

https://doi.org/10.31174/SEND-PP2018-173VI71-09

\begin{abstract}
In the paper the results of the study on the features of teaching foreign language and information literacy to the "third age" people are presented; various age characteristics and general recommendations on teaching the elderly are offered. A brief analysis of the recent research and publications on the given issue is provided. The global trend of the lifelong learning and the development of the "third age" Universities are updated. Contradictions that determine the theoretical and methodological problem of scientific and methodological support of the "third age" education are defined. The process of developing assertive behavior skills among the elderly while studying a foreign language, challenging yourself in the world of information resources and mastering confident behavior skills within the interpersonal relations is described.
\end{abstract}

Keywords: foreign language education, foreign language learning, information literacy, communication, assertiveness, assertive behavior, elderly people.

Introduction. As the advanced age has come, the level of vital activity decreases, self-perception changes and selfesteem becomes lower. People of such age often feel that their life has no sense. They are also depressed by the financial difficulties. However, social problems are of utmost importance at the advanced age, since social relations are changing greatly after the retirement.

Typical problems of the elderly and their influence on them:

- social circle is usually greatly reduced after retirement. People of the advanced age suffer from loneliness, they often have no one to chat with, to share their feelings and thoughts. They want to feel somebody's concern, but do not get it;

- retired persons are often faced with disrespect, brutal and disdainful treatment. Many younger people often negatively treat the elderly, considering them a burden for themselves and for the society;

- with the death of their friends and age mates, pensioners receive a great blow. Their social circle becomes even more limited, leaving a strong sense that life has come to an end.

These social problems of the elderly have a great influence on their emotional state and well-being.

Change of the regular way of life is a critical moment in the life of an elderly person. Unpredictable situations, new people, unusual circumstances, obscurity of social status - these life circumstances force a person not only to adapt to the surrounding environment, but also to react to changes within himself. The elderly people are faced with a question of estimating themselves, their opportunities under new conditions. The process of personal adjustment is very painful and difficult. It is known that at the advanced age the defective memory and loss of alertness, decrease of ability to be aware of a new situation, anxious mood and emotional lability are observed. One of the main features of the elderly is the psychological vulnerability and the growing inability to deal with various stress. Therefore, people of the advanced age are characterized by their special sensitivity to getting the attention, moral and psychological support.

The best way to help the elderly person is to provide him with constant support and a circle of communication, teach him something new and interesting. It is an important part of social work with the elderly.
The research on the personal, cognitive and cultural potential of the older generation proves that under certain circumstances their ability to study even rises instead of decreasing. The need to involve the elderly into the educational process is, first of all, due to a number of sociodemographic factors [1-3].

It is worth mentioning the special features of working with the elderly population in Ukraine - it is provided through a system of social institutions, among which are the territorial social service centers, residential facilities (geriatric homes), public organizations, educational institutions.

According to the European Union standards [4], it is necessary to create such conditions that would not only provide public support for the elderly, but also stimulate their activity.

One of such methods of activating the elderly is the Third Age Universities that successfully operate in many countries of the world. Created at higher educational institutions or public organizations, they implement the principle of a lifelong education for a person.

In 2009 in Ukraine, with the support of the UN Population Fund, a draft Concept of Development and Provisions for the Third-Age Universities were developed. Since 2011, the social pedagogical service "The ThirdAge University" has been operating in Ukraine, its activity is being regulated by the Order of the Ministry of Social Policy of Ukraine № 326, August 25, 2011 "On the introduction of the social-pedagogical service "The ThirdAge University".

At the Third Age University, every retired person is surrounded by other elderly people with the same interests and similar difficulties they are faced with. He can always share his joys and sorrows and just spend time together, study a foreign language, learn to dance, sing, etc.

As part of our study, we monitored the activities of the Third Age Universities and identified the main teaching methods: lectures, workshops within interest groups, selfeducation and mutual-assistance groups, excursions, and so on. The most popular classes are: "Foreign language", "Decorative and applied art", "Valeology", "Social communication training", "Information and communication technologies". It turned out that one of the main problems of the "third age" people which prevent them from a successful social life is the uncertainty in their own behavior. 
Therefore, an important issue for the theory and practice of overcoming and preventing such uncertainty among the elderly is the development of assertive behavior skills.

Brief review of publications on the topic. The analysis of recent studies and publications showed that the assertive behavior promoting self-development of the personality had been the subject of research of a range of domestic and foreign authors. The issues on the specifics of social work with the elderly are studied by E.I. Kholostova, who investigates the life activity of the elderly, describes the advanced age as a social problem [5, p. 5673]; V. M. Moshennik, who studies the theory of the old age and the principles of social work with the elderly; I. D. Zvereva [6, p.341] explores the levels at which social work with the elderly is carried out and the principles of this activity; L.A. Yakubova studies the peculiarities of the organization of social assistance to the elderly [7] etc.

Goal. Our research is aimed at studying the problem of assertive behavior skills among the elderly in the process of studying a foreign language, mastering the skills of confident behavior within the interpersonal relations, getting acquainted with modern information technologies.

Materials and methods. According to the objectives, a complex of research methods was used to identify socially significant integrative properties of assertiveness of the personality in the cognitive, emotional-volitional and behavioral spheres, including: observation; formative experiment; cross-sectional and vertical research and the battery of personality tests: "Diagnosis of self-confidence level", "Motivation for achievement", "Personal assertion level", "Self-affirming behavior", "Will power development".

Results and discussion. Under assertiveness we mean personal ability and readiness for free communication with different people, expression of thoughts, feelings and desires clearly, conscious behavior management, friendly regulation of interpersonal relations.

Assertiveness as an integrative property of an individual, influencing social presentation and success, is close to perceiving personal feelings and feelings of other people. At the advanced age, there is a huge need, necessity to integrate different manifestations of the self-identity, but for this integration, another person is needed $-\mathrm{a}$ force that provides psychological information for self-integration.

At the third age the interpersonal problems are also very common, among them: reduction of behavioral control, which leads to advanced egocentrism, sensitivity to offense, impatience of contradiction, suspicion, "sharpening" of personality traits, lower emotional control and voluntary behavior, which leads to problems within interpersonal relations.

A frequent companion of the elderly is the feeling of "loneliness" due to the lack of their social ties. Feeling of loneliness is generated by the dissonance between person's true self and the way others see him. They usually blame themselves for the long-lasting loneliness. Lonely person needs social connections, but only those he can regulate on his own, not the imposed ones.

We distinguish the following assertive components: appropriate assessment of the situation, rational variation of the action methods and the productive transformation of problem situations (flexibility of thinking); forecasting of self-development and self-movement, self- identification in the surrounding world on the basis of realizing the sense and values of your life (life-purpose orientation). Assertive behavior makes it possible to express your thoughts clearly and unambiguously, act morally and convincingly, avoid manipulation, understand yourself and others, be able to promote your interests. Thus we can argue that assertiveness is an adequate assessment of the situation and your behavior, a way to selfrealization.

In the sphere of interpersonal relations, the assertive behavior implies freedom from relying on others' opinions and evaluations, cultivation of spontaneous behavior in accordance with your own mood, motives and interests. Under the concept of "assertive position" an effective way to resolve the conflict situation in the system "Social worker - an elderly person" can be viewed. Such position gives relief from authoritarianism and develops a sense of responsibility within interpersonal relationships. Assertive behavior of elderly people also involves the development of confidence and positive attitude.

The elderly people who do not have relatives, close friends, are more likely to demonstrate uncertain or aggressive behavior. That is why development of assertive behavior skills is very important for successful social and psychological adaptation of the elderly. Social workers of the Third Age Universities are obliged, whenever possible, to develop the skills of a confident refusal in safe situations among the elderly during special training workshops. Most commonly, the uncertainty manifests itself, as uncommunicativeness, shyness, calmness, and intimidation. The main thing in the work of social specialists is to direct the activities of the elderly and to regulate their interpersonal relationships. Communication is valuable when it causes the need to share thoughts, promotes the manifestation of attention and sympathy to others. Since older people do not have enough experience in effective interaction with social workers and other elderly people within the third age universities, they accordingly have no confidence in their own efficiency. In addition, such lack of confidence is often associated with human health. The state of human health is of particular importance in the process of education; loss of hearing and reduction of visual acuity is an obstacle in getting new knowledge and skills.

We conducted the research from January 2017 till July 2018. Participants were 284 people aged 61 years and older [8]. A special program was developed to promote the skills of adapting to new conditions.

The "Self-improvement" training program has several directions: foreign language education and development of information competence for the elderly. The program creates conditions for psychological and pedagogical support and self-development of the elderly. Defining the priorities for the formation of assertive behavior of the elderly, we can distinguish the ability to surf in the world information resources and promptly find all the necessary information. In this regard, within the "Selfimprovement" course the following special courses are introduced: "Computer fundamentals", "Digital lifestyle and effective communication."

In terms of our research we also studied the way the English language courses for the elderly are organized within the Third Age University. In 2017750 elderly 
people were registered for training, 310 of them started to attend classes, and 213 attended all the classes [8].

The analysis of the questionnaires of the experiment participants showed that the vast majority of the elderly people chose English language courses in order to communicate with other people $(65 \%), 25 \%$ for personal development and $10 \%$ - to maintain proactive approach to life.

It was found that the elderly people with assertive behavior are independent and self-sufficient, which is manifested in various life spheres, but most obviously - in the sphere of interpersonal relations, in communicative situations (the ability to freely express thoughts, feelings, communication at all levels).

Especially important for the third-age University students is the simulation of conditions for self-confidence development. That is why, the optimum conditions for this are created within the course "Self-Improvement", which helps to increase the number of possible patterns of behavior, develops communicative skills of the elderly and promotes correction of interpersonal relations, and their social adaptation. Thus, after completion of the course, the group admitted the loss of situational and personal anxiety, as well as an increase in the level of assertive behavior.

Conclusions. Modern research proves that the ability to learn among the elderly, in particular the acquisition of a foreign language and computer literacy, under certain conditions even rises instead of decreasing. One of these conditions is overcoming the age-related stereotypes. Thus, there is a hypothesis that the brain of an elderly person loses the ability to build new relationships. This very hypothesis was widely used to explain the difficulty of mastering foreign languages and information technologies by the people of advanced age. Some of the provisions of this hypothesis can be found even nowadays, although neuroscientists have proved that under certain conditions, the elderly can study and acquire new knowledge even better than at a young age. One of the important conditions for teaching the elderly is taking into account the age peculiarities and state of health, the assertiveness of the individual, clear definition of the purpose and the need for communication, the use of information and communication technologies in everyday life, mobility.

It is necessary to emphasize the importance of the development and formation of assertiveness as a personal quality. After all, assertiveness involves self-confidence and confidence in future due to the ability to take responsibility for both positive and negative situations in your life; freely express your thoughts and feelings without violating others' rights; openly, honestly and adequately communicate with people on equal terms, paying attention to them, showing respect and empathy. Confidence, as an important condition for constructive self-actualized behavior, affects not only communicative but also informational mobility, which helps to reduce desadaptative behavior and increase person's adaptation into social environment. Therefore, these features of assertiveness contribute to the development of study skills of the elderly, including foreign languages and information literacy.

\section{REFERENCES}

1. Fedorenko S. A. "The Third Age" Universities as a part of lifelong learning; foreign experience / S. A. Fedorenko // Pedagogical process : Theory and practice. - 2014. - Vol. 1. - P. $133-138$.

2. Savelchiuk I. B. Innvation methods of social work with the elderly: specifics and peculiarities of implementation / I. B. Savelchiuk // Young Scientist. - 2015. - № 2 (17). - P. 95 98.

3. Skoryk T. V. Social and pedagogical effect of the third age university / T. V. Skoryk // Young Scientist. - 2015. - № 2 (17). - P. $117-123$.

4. http://azovacademy.ucoz.org/publ/stati_i_nauchnye_publikaci i_articles_science/evropejski_standarti_pensijnoji_sistemi_ja k_viznachalni_chinniki_formuvannja_socialnoji_sferi_v_ukr ajini_r_p_luckij/1-1-0-112

5. Lukianova L. Main features of the adult education / L. Lukianova // Adult education: theory, practice, prospects.

- 2009. - Vol. 1. - P. 72 - 80. - Access mode: http://nbuv.gov.ua/UJRN/OD_2009_1_11.

6. Pavlova Iu. "Lifelong learning" principle as a necessary condition for the health care and support of the elderly (based on the example of the third age universities) / Iu. Pavlova // Young sport science of Ukraine. - 2013. - Vol. 4. - P. 117 123.

7. Fachlexikon Deutsch als Fremd- und Zweitsprache / Barkowski H., Krumm H.-J. - Tübingen, Basel : A. Franke Verlag, 2010. - $370 \mathrm{~s}$.

8. Viktorova L., Kocharian A., Korotun O. Technologies in foreign language education for the "third age" learners Information Technologies and Learning Tools. 2018. Vol 63 №1. - P.22-35. URL: https://journal.iitta.gov.ua/index.php/itlt/article/view/1940 